\title{
SOCIETY'S USE OF THE HERO FOLLOWING A NATIONAL TRAUMA
}

\author{
Elizabeth Goren
}

The terrorist nature of the attacks on September 11th, the number of deaths on American soil and the direct involvement of society as virtual eyewitnesses of the events of that day had a traumatizing impact on the cultural consciousness. The interpersonal, socio-cultural manifestations of traumatic grief are explored through an analysis of the creation and transformation of its national heroes, the New York City firefighters, in the public mind over time. Mechanisms of identification, dissociation and splitting were manifested through the erection of physical and social boundaries around 9/11, which allowed for idealization at a safe distance followed by de-cathexis when the collective sought to abort the mourning process and overcome the pain and helplessness of traumatic grief by going to war.

KEY WORDS: heroes; society; trauma; grief.

DOI:10.1057/palgrave.ajp.3350013

Just wearing a uniform doesn't make you a hero.

Firefighter Sean Cummins in the New York Times 4/16/02

The heroes created out of national catastrophes are a barometer of the collective's moral and emotional state and conflicts. How the image of the hero evolves over time tells us more about the psyche of the society at any given moment than about the individual or group identified as the hero. Psychoanalytic literature on trauma has largely focused on individual psyche, in particular, studying individual survivors and other victims. In this paper, I would like to draw attention to the collective psyche, specifically looking at the national crisis arising from the terrorist attacks on September 11th through a study of the evolving relationship between society and the firefighters of New York City, those donned as the main heroes of the day. It is my contention that the firefighters were chosen as the appointed heroes because they represented a symbol that combined the personifications of society's complex and conflicting emotions surrounding 9/11. Made into an iconic figure of the classic tragic hero, the NYC fireman became a place

Elizabeth Goren, Ph.D., is Faculty, New York University Postdoctoral Program in Psychoanalysis and Psychotherapy, and also in private practice in New York City.

Address correspondence to Elizabeth Goren, Ph.D., 300 Mercer Street, Suite 23L, New York, NY 10003; e-mail: elizgor@aol.com 
marker and repository for the catastrophic loss, victimization and trauma felt by the collective while also symbolizing our courageous refusal to accept defeat in the face of death and defeat.

As Cowen (2000) pointed out, "Heroes, by their very nature, serve as highly visible and sharply focused reflections of various qualities in their societies, including the moral," and claimed that societies "use" heroes as role models "for their own purposes." Bennett (2004) has put forth the thesis that the hero is created by a society as "a collective response to.... helplessness and dread of loss." Further, he argued that in society's "hunger" for heroism, heroes function as a source of "vicarious relief" for the "unbearable emotions" of the society it serves. I will explore some of the conditions specific to $9 / 11$ that contributed to create a national psychological crisis, including the national scale of the terrorist attacks, the massive number of deaths and enormity of destruction, the role of technology and the media, which contributed to the collective need to locate symbols that both contained and manifested the complex, often conflicting emotions of society.

As a volunteer in the recovery and relief effort at Ground Zero, then as a psychologist working with the FDNY, I became as much of an observing participant as I was a participant observer in the changing attitudes towards the firefighters and in the interpersonal barrier that mirrored the physical barricades erected around the disaster and which functioned as a mechanism for society at large to defend against overwhelming experience. This endowed the firefighter heroes with enormous social valence, but put an impossible burden on them of serving as the channel for society's trauma, grief and loss of self-esteem.

\section{AMERICA BEFORE}

Prior to the morning of 9/11, America was enjoying a peacetime period of unusually strong economic strength and stability, attributed in large measure to the role of technology. While still looking to technology as the golden key to progress, the collective was becoming disturbed over the growing gap between the technological achievements and coming up with ethical systems that adequately address the moral questions raised. Claims of America falling into a moral vacuum had begun a groundswell of appeals to organized, more fundamentalist religion with its more conservative values and moral traditions not only abroad, but also within their own borders. While globalization had initially meant Americanization abroad, it was now becoming less clear who was absorbing whom. America's worldwide hegemony was less certain and our collective self-image in flux. 
With this, America's concept of hero was also shifting and floundering. While historically the cultural concept of heroism "has been subject to cyclical ups and downs" (Hein, 1993), the tradition of heroes was radically altered in the 20th century. The loss of the traditional hero has been variously attributed to the "mechanized butchery" (Hein, 1993) of World War I, the "collapse" of "the timeless universe of symbols" by "the power driven machine" (Campbell, 1976, p. 27), to the Vietnam war and the period of postmodern disillusionment (McGinniss, 1976). McGinniss proclaimed that

We did not have heroes any more because of the Sixties. Or because of television...Or...the computer. Or...the atomic bomb... Or Vietnam.... Freud...Marx... Watergate.... Take your choice. By $1974 \ldots .$. The truth was, we did not have heroes any more because there were no heroic acts left to be performed. (p. 21)

An eerily accurate forecast of the cultural environment which prevailed up to $9 / 11$. Iconic heroic images had come to represent our super egos, more than our superegos, heroes symbolizing fame, fortune, youth, beauty and prowess and the celebrity had come to largely replace the traditional hero in America. In our media saturated culture, where no one person or idea can hold the public's interest for very long, heroes have become even more vulnerable to the inherently ephemeral nature of hero worship. Witness, for example, Lance Armstrong, exemplar of today's hero, the celebrity super athlete, conqueror of cancer and seven time champion of the Tour de France, and married to a celebrity pop star, who recently claimed that one of the reasons for his retirement from professional sports while still a winner was because of his awareness of the vulnerability of today's sports hero to the evanescent nature of the public's interest.

Whether the phenomenon of celebrity as hero reflects the primacy of fame and fortune as culturally shared values or the lack of a strong collectively shared moral compass is hard to say. But the moral and emotional crisis in America caused by the terrorist attacks on 9/11 did result in an immediate return to traditional heroism.

\section{September 11th 2001}

On September 11th, the enemies of freedom committed an act of war against our country. Americans have known wars—but for the past 136 years, they have been wars on foreign soil, except for one Sunday in 1941. Americans have known the casualties of war-but not at the center of a great city on a peaceful morning. Americans have known surprise attacks but never before on thousands of civilians. All of this was brought upon us in a single day - and night fell on a different world. President George W. Bush to the American people, September 20, 2001 
By virtue of the level and extent to which communication technology has been incorporated into daily life, millions of Americans and others around the globe watched the catastrophic events of September 11th unfold before their eyes in real time, becoming 'virtual' eye witnesses to mass murder, "catch(ing) death actually happening and embalm(ing) it for all time...(as)...only cameras can do" (Sontag, 2003, p. 59) onto our collective psyches. Sontag pointed out that the transformation of the American living room into the "home front" for "battles and massacres" (p. 21) and a "routine ingredient of the ceaseless flow of domestic, small-screen entertainment" (p. 21) began in the Vietnam era. It was one thing to be a "spectator of calamities taking place in another country" (p. 18) but altogether another matter when the "tele-intimacy with death and destruction" (p. 21) to which we had become accustomed, if not inured, were catastrophic acts of terrorism on American soil. This fact was significant in rendering 9/11 a traumatic moment for the society as a collective.

Americans felt morally and emotionally compelled to keep watching and reliving the events as they were being unremittingly replayed over the television and computer for the days and the weeks following 9/11. This virtuality effecting what Elsaesser (2002) has described as "metaphysical double takes" (p. 62) on our sense of reality and identity, leaves the populace feeling totally involved but simultaneously helpless. By virtue of our role as cyber-spectators in real time, we felt as though we had participated in and therefore were in some way party to the deaths and destruction. In this way, September 11th was a unique moment in American history, a pinnacle and nadir in scientific and social evolution whereby one of our greatest achievements, the airplane, once a symbol of America's ingenuity, heroic power and freedom, was enjoined into a whole new form and level of destructive use. Man merged with machine as suicide bombers using jet planes to imprint their destructive power on the collective's psyche, transforming the airplane from a symbol of American strength into a symbol of our victimization and impotence.

Like spellbound rubberneckers sharing a surreal nightmare, we at once felt detached yet utterly gripped in as reality, common to experience that mediated through the lens of communication technology (Goren, 2003). As individuals and as a collective, we were desperately trying to grasp and assimilate the incomprehensible reality of thousands of people literally vaporizing before our eyes in a matter of moments. Our state of disbelief and mass helplessness brought a moral crisis where many core American assumptions, particularly a shared belief in the nation's invincibility, were challenged when several major symbols of American strength were brought down, and we watched the Pentagon in flames, a commercial airplane crash in Pennsylvania with no survivors, and the towers of the World Trade Center collapse in seconds-the 
South Tower in nine seconds, and half an hour later, the North Tower in eleven seconds. The persons, the single group the world witnessed emerging from the carnage, were the men of the Fire Department of New York in full firefighting gear. Our vision of them epitomized the culture's existential crisis. For the existential hero, as Becker (1973) defined him, is the "man who...Go(es) into the spirit world, the world of the dead, and return(s) alive" (p. 12).

\section{TRAUMA CREATES A HERO}

Certain factors surrounding the events of 9/11 conspired to intensify the need for symbols, especially for heroes: the traumatic and terrorist nature of the attacks, the massive loss of life and the number of Americans involved as helpless witnesses. If we define trauma as that which "overwhelms and defeats...the cultural psychological assumptions governing our lives" (Laub \& Auerhahn, 1993), the impact of $9 / 11$ was arguably of traumatic proportions not only for many individuals but also for society as a whole. The fact that the catastrophes were deliberately inflicted by acts of men rather than of nature further contributed to their traumatizing, terrorizing impact.

Bennett (2004) suggested that in social trauma, "especially sharing in the witnessing of the horror and danger that the hero undertakes to fight", as was the case with the country's watching the firefighters in their valiant rescue and recovery efforts, the group develops defenses to "process and master...traumatic repetition of the passivity and helplessness of watching." This includes the appointment of heroes who function to "provide... vicarious relief of those unbearable emotions" for the collective. The motivation and inevitable effect of terrorism when it succeeds is the induction of a generalized fear, which takes away any sense of predictability, leaving people never knowing where, when, or how the next strike will come. The intended target is robbed of anything to hang on to, but the dread of anticipating further attack. The invisible, un-specifiable but very real specter of continued terrorist threat in the first days after 9/11, combined with the incomprehensible reality of the virtual disappearance of thousands in a matter of minutes, to intensify the need for a symbol, as something one might look to, hold on to, something to formulate and express all that society could neither apprehend nor articulate directly. Distressed and shaken in confused, frightened grief we were even unsure as to what the symbols needed to represent. Elsaesser's (2002) essay on the role of the visual image and communication technology is relevant here. He states

Political or social events whose momentous significance we instinctively intuit, television turns into happenings...terrifying surreal collages, only to return to them tomorrow as stories and narratives: with heroes and villains... and morals to be drawn. (p. 62) 
So American society constructed several symbols-for enemy, hero, survivor and victim. These multiple symbols served to concretize all that was seen that could not be perceived, all that was heard that could not be listened to, and other fragmentary not yet cohered thoughts and feelings. The most evocative symbols of the moment were those of the enemy and hero, splitting our emotions into opposing personifications of good and evil. Al-Qaeda, led by Bin Laden, became the symbol of evil, and the American flag the symbol of good. Unfurling flags over homes, automobiles and public buildings, renewed a tradition that had long ago grown out of favor, now signified a traumatized but proud nation in crisis. In this split, American society could cathect the range and enormity of feelings it was undergoing onto the firefighter as hero, a symbol representing duality of death and life, victim and rescuer, loss and triumphal survival.

As the weeks turned into months, through our collective pain, we kept watching the men of the Fire Department of New York, who represented the organization that had suffered the greatest number of losses and were most involved in the rescue and recovery effort, relentlessly enter and return from the ineffable, the shadow world of death and destruction of the former twin towers that came to be known as Ground Zero. These men, like Ground Zero itself, were imprinted with a visceral reality those outside could only imagine, a reality so disturbing most people could only psychologically approach it from a distance, further deepening the experience of the catastrophe as a disembodied super-reality. The firefighter survivors of the shadow of death were the most visible manifestation of both presence and absence. Initially we endowed them as mythological carriers of a truth that was branded on their broken faces and stooped indomitable bodies. In those first weeks, people longed to brush them as they brushed death, to touch them to understand, through as direct contact as possible, the crushing reality of what had happened. The impulse for tactile sensory contact may have also been motivated by an effort to utilize the fireman as a kind of transitional object (Kaftal, personal communication) in a healing function. Contact with them in their loss provided a Winnicott-type comfort for us in coping with our own loss. Thomas (2005) similarly described a kind of fetishistic form of attachment to the firefighters in this initial post 9/11 period, "touching" the firefighters offered the promise of restoring strength and "wholeness" to us as a society. The firemen became love objects of a sort. Firehouses were flooded with gifts, letters of thanks and donations. The media swarmed around the men and firehouses with paparazzi frenzy, and people from far and wide came to see, touch and cry with and for the firemen. Pouring our emotions into the FDNY, we had a place and person 
onto which to express our grief, and a reason to believe in the possibility of redemption.

But since heroization is an interpersonal phenomenon, no discussion would be complete without mentioning how the objects of the heroization, the firefighters themselves, experienced their sudden lionization into hero status. While the hero, as a product and instrument of society in its shared coping efforts, cannot exist in isolation, ironically the actual experience of being a hero often involves feelings of isolation, and a paradoxical alienation from the very people who extol him. This was clearly evident in many firefighters. First and foremost, it is important to note that the firefighters did not consider themselves heroes. Despite having successfully evacuated tens of thousands of civilians out of the two towers, they felt that they had failed to save the lives of 343 of their fellow firefighters and three thousand civilians. The only real heroes of the day in their minds were their fallen brothers, who had sacrificed their lives knowingly in the effort to save others. Over and over, I was repeatedly told, by one man after another, that he did not consider himself a hero. The reasons they gave were simple: "I was just doing my job", "I ran like a bitch just like everybody else", "I wasn't even there that day", "No mayday was called".

As a group, they were fairly sanguine about the public's anointment of them as heroes. Though many firefighters expressed compassion for what they instinctively understood as society using them as the repository for their own grief, they had also intuitively anticipated their inevitable fall from grace. Some expressed resentment and feelings of being exploited by the public's use of them as kind of emotional place marker for the community's feelings. Though, as in any group, there were individual firemen who craved being in the spotlight, for the most part the men experienced the constant media attention as depriving them of the time and ability to mourn in private. Accustomed to occasional bursts of public attention, they often talked about how short lived the public's love affair with them would end up being. As one man predicted with eerie accuracy, "When the dust settles, we'll be as interesting as the next bit on the eleven o'clock news" (Goren, 2004), and another, "Yes today we're heroes, but tomorrow we'll be zeroes" (Goren, 2004). In less than 2 years after the events of $9 / 11$ the media portrayal of the firefighters had shifted to that of the fallen heroes, with news stories shifting to titillating reports of sexual misconduct and brawls inside firehouses, alcohol and substance abuse, aggressive run-ins with the police (e.g. Wilson \& McIntire, 2004). Our heroes had so fallen in the public eye that the new mayor Michael Bloomberg felt no compunction about disdainfully warning New York's Bravest to "look in the mirror" and stop "turning a firehouse into a brothel" (Wilson \& Mclntire, 2004). 
This kind of fall from grace can be solely explained by the disillusionment that naturally follows idealization. If we look closely at the evolution of the culture's reaction to what happened, there were subtle but definite signs of psychic and interpersonal distancing, which began fairly soon after the disaster as part of a collective coping strategy. Creating heroes served as a form of cathexis, a symbolic repository for the public's emotions, in a way that insures a separation, albeit one of idealization, between the person who is a hero and those who valorize the individual as a hero. Heroization, thereby, functions as a form of psychological and social containment.

\section{BOUNDARY MARKERS AND SOCIAL CONTAINMENT: GROUND ZERO}

The first signs of emotional distancing were perhaps most clearly manifested in the actual erection of physical barriers around the disaster site itself, and in the boundaries media created around the disaster. For the first week after 9/11, every national television network was devoted almost entirely to the crisis. Print and broadcast media were continuing to feature daily news from Ground Zero for months, but after a week, national networks declared an official returning to 'regular programming' as a patriotic effort to return to 'normal life.' Though the national mantra of 'everything had changed' would continue, as it has done to this day, people also began speaking of the need to return to 'normal life'. Shortly thereafter, by October, the nation and national media's eye was dramatically turned away from the catastrophe with the initiation of the war in Afghanistan.

The internal distancing was mirrored by a strongly perceived invisible experience of separation that developed between those outside and those within the zone of disaster. People identified as inside the disaster, in particular, the recovery workers and those individuals who had been the most exposed and most affected on 9/11, were perceived, and in many cases perceived themselves, as contaminated carriers of the catastrophe, who had to be almost quarantined, kept at a safe distance from those outside the impact of the disaster to avoid further social contagion. In this period, the public carried mixed emotions towards those bearing the catastrophe's aftereffects. These ranged from empathic and altruistic feelings, relief (' $\mathrm{I}$ 'm glad it wasn't me'), to conscious fear of contamination ('I can't get too close or I'll get too upset'). Those inside were undergoing their own sense of separateness and alienation. This was exacerbated by their sense of the outside world's distancing from them, to the point that they began to feel more objectified, as hero objects to be idolized or victim objects to be pitied, than genuinely empathized with by the public.

With the carriers of the catastrophe at a more emotionally safe distance from the non-contaminated, several other factors came into play to deepen 
the interpersonal distance: individual sensitivity to culturally authorized social distancing and characterological propensity for dissociation, the universal instinctive dissociation from extreme pain, the socially shared irrational fear of contagion that commonly follows social disaster (Erikson, 1995) and finally an American discomfort and devaluation of prolonged states of mourning.

The very act of naming the disaster site Ground Zero and cordoning it off with a fence, constituted enactments of the psychological impulse to contain and confine the horror. This was also evidenced in moving the relief centers for victims and their families away from the defined disaster zone to locations further uptown. While these actions were meant to alleviate the pain of being reminded of problem of association, they also functioned to reduce the effect of having endowed the site and those working within it with frightening magical powers of contagion. With Ground Zero blocked out, away from sight if not sound, in the daytime, one could literally block out the reality of the whole situation. At night, however, it was harder to block out the lights that flooded the site or the sounds of the forklifts and trucks moving around inside Ground Zero. And for those within a certain distance, if the wind blew a certain way, our most primal and powerful sensory of the sensory systems, our olfactory sense, imprinted the aftermath of the catastrophe on psyche and memory. While the military and police presence remained strong downtown, for most Americans, and for those New Yorkers who were not "down there," life had resumed at least a semblance of routine and appearance of normalcy.

The experience of the city as a war zone was even more markedly reduced once the war in Afghanistan began in October and the action and our focus were transferred beyond our physical and emotional borders. A parallel phenomenon took place inside the city at this time with the transfer of the relief centers away from the site. For example, about a half mile uptown at Pier 94, a white tufted tent used for special events and possessing a Camelot like charm was converted to a carefully cordoned off massive relief center for victims and families, more suggestive of entertainment than trauma or disaster to the uninitiated eye. The sanitization and efficiency toned organization of the massive relief and recovery effort was geared to restore a sense of order and containment. The city itself, having been targeted as a symbol of American strength and a seat of financial power, had suddenly become a symbol of our national vulnerability and defeat. Underlying these manifest efforts at recovery was a quiet collectively shared unconscious conspiracy of containment-containing the damage, death and horror to contain the trauma, and prevent further spread of the trauma to those less impacted. In the conflict between the competing impulse to 
see and touch versus avoid the people and place most closely connected to the disaster, the impulse to separate was winning out in the public mind.

This was most evident in the direction of population movement in this period. On September 11th and in the first days after there was a massive influx of people rushing in to help. Thousands were turned away. Within a few weeks, the flow of people reversed. Not only were people no longer trying to come in but also thousands began to leave. City residents fled in droves, some claiming the need for a 'vacation,' a huge number relocating either temporarily or permanently, expressing the need to 'get away' from the constant reminders of what had happened and their concern about a second attack. Outside the city, people seemed content to have the physical and human symbols of national trauma and defeat at the safe removal of the television set. Tourist and business travel into the city suffered dramatic losses, causing a major economic downturn in the city, as New York City became a symbol of destruction, loss and potential vulnerability for further terrorism.

These were some of the first clear signs of active psychic and interpersonal distancing at a mass social level. Those traversing the boundary between the world outside and the world of those living the aftermath of the trauma were witnessing dissociation and repression taking place before their own eyes. Talk began of the need to forget, to "move on" and "put it behind us." Dissociation was hidden and partially rationalized beneath the unassailable concerns about possible further terrorist attacks.

By the time tourists began to return in the spring of 2002, Ground Zero was converted into an "attraction," which was designed more like a special museum exhibit than a catastrophe. The throngs of visitors to Ground Zero were carefully funneled through an elaborate system of ticket assignments with scheduled hours of admission to a viewing platform, endowing the experience with an inherent emotional distance. This image contrasted starkly with the far more visceral images and sense memories of the site in the first days after 9/11 and which remained with those living and working in and around the disaster-the sight of the five story high mound, the vision of crushed automobiles, dust and ash everywhere, the sound of forklifts and trucks moving in and out, and the unique horrific odor of human incineration and the jet fuel burning in the mound of metal, concrete and glass.

With the external barrier from the trauma site solidly defined and confined within Ground Zero by the removal of the physical evidence of the destruction (airplane parts, luggage, layers of dust, etc.) and a layer of normalcy restored to lower Manhattan, the sight of the indelibly damaged people took on a subtle but definitive change in public perception. The shift from 
'seeing is believing' to an unconscious revulsion in relation to the site of trauma extended to those persons most associated with the disaster, including our hero victim/survivors, the firemen. While initially iconographic superheroes, the firefighters began to undergo the vicissitudes of being alternately treated like superstars, with people wanting their autographs and photographs, to being treated more like pitiable tragic figures. The firefighters themselves were preoccupied with working inside Ground Zero and fighting to keep the recovery effort going amidst growing political and economic pressure to end the operation. In a state of chronic exhaustion, working extra shifts because of the massive loss of manpower as well as down at Ground Zero, the firemen did not feel in any way powerful or heroic. Rather they continued to struggle with a profound sense of failure, not only in not having been able to save thousands of lives or to recover the bodies of those lost, but then also in not being given adequate time to recover the remains before the closing of Ground Zero.

As a therapist working with so many people who lived and/or worked near the site, with people who had witnessed the events of $9 / 11$ or been directly involved in the relief or recovery operation, I found myself, at times, being identified and treated with ambivalence, as someone both tainted by the trauma and to be avoided, yet also as some kind of hero myself to be admired for my involvement. A number of my private patients openly acknowledged their hesitation to return downtown where my office was located, and many expressed their mixed feelings at seeing me, a person they associated with the disaster. Like many of the relief workers, survivors and victims, I too felt a protective impulse to spare those outside the zone of the disaster, in a developing breach and sense of distance from those who seemed to have not been viscerally impacted by the disaster. Traveling between the world within and beyond the zone of trauma, I became an inside outsider.

In this quiet, but powerful barrier that developed between those inside and those outside the disaster, a pronounced change took place in the public's attitude to our heroes. With the rubberneckers' shift in gaze from fascination to revulsion, outsiders were content to corral these trauma carriers away, to idealize them from afar. Those who were bearing the impact of the trauma, in particular the firefighter heroes, started to feel objectified and more like eyesores than idealized figures in the public's mind. Knowing their dispirited faces belied the city's effort at a face lift, they felt more and more separated and alienated from those 'moving on' outside. Those inside the disaster zone bonded in the shared of sense that "no one who wasn't really there could understand". Their awareness of the ambivalence of the public toward them further contributed to the sense of 
isolation inherent to grief, congealing into alienation and a sense of objectification by being put into a depersonalized role of a hero.

However, when by the spring of 2002, the public no longer sought as much contact and involvement with them, the firefighters felt a relief from the exposure of being in the spotlight, and of the pressure to live up to the public's idea of them as heroes. That is, for being the kind of heroes, they felt they neither had been nor were able to fulfill the responsibility they had been given, to function as a channel for the community's sorrow, guilt, helplessness, and pain. Finally, they had the privacy they sorely needed to mourn together and as private individuals.

\section{THE WAR BEYOND OUR BORDERS: CREATING NEW HEROES}

Less than 6 weeks after September 11th, the war zone was officially moved from within the US borders physically and psychologically to far away when we initiated the war in Afghanistan. The 'shock and awe' of those first bombs exploding in Afghanistan successfully drew the public gaze and preoccupation away from the aftereffects of 9/11 that were still manifestly evident at Ground Zero. In creating a new front line and new heroes on whom to focus our attention, the cultural climate was shifted from one of tragedy and defeat to renewed hope and sense of empowerment. Going to war so shortly after 9/11 aborted the mourning process midstream, and transformed feelings of helplessness and vulnerability into anger and revenge. This culminated in the war in Iraq in 2003, and the eventual downfall of the firefighter as hero. In our impulse to dissociate from our pain, in the need to feel powerful rather than helpless and victimized, as we had so acutely felt in the immediate aftermath of 9/11, the country sought out heroes who symbolized invincibility, those of the American military. The fighting soldier was representing the ultimate warrior symbol. By going to war, we could identify with and embrace warriors rather than valiant but fallen rescuers.

The extent to which initiating war was a cause or consequence of the unconscious collective response to the grieving process is an important question beyond the scope of this discussion. A death-averse culture, we are not a society given to prolonged mourning, and death does not figure broadly in either our self-image or our rituals. In contrast to societies in whose histories massive loss of life through war, genocide or other social catastrophe have figured prominently and have informed their cultural consciousness and established rituals of national mourning, America's consciousness was founded and has remained based on freedom, safety, and invincibility. Additionally, America's self-image as a can-do, efficient and productive, never-say-die approach to life translates to a rather 
perfunctory and matter of fact attitude to what we treat as the 'business' of death and mourning, and, until 9/11 toward the notion of trauma and disaster. The multiple factors of our national identity of power, our disapproval of prolonged emphasis on vulnerability and death-related issues, and the universal self-persevering impulse to dissociate from the active pain of trauma, combined to create the conditions ripe for the kind of personal and interpersonal distancing, which was punctuated by going to war, first in Afghanistan and then in Iraq.

Elsewhere I have reported on the difference between the responses to the bombing of Afghanistan between those working inside Ground Zero and those beyond its perimeter (Goren, 2002). While national television blared the bombing and reported the public's support, inside Ground Zero, there was no applause and no expression of anger or cheer for the spectacular strike of revenge in the Bin Laden search and destroy mission in Afghanistan as was reportedly occurring outside. For the most part, the men and women relief and recovery workers appeared almost unimpressed by the counter attack across the world, for those working at Ground Zero were still in the shocked flatness of death immersion. A few expressed an unenthusiastic support of the action, others just shook their heads and commented on how little it had to do with what they were doing, deepening the psychological barrier between those inside and outside Ground Zero's boundaries. The difference in the two groups' attitude and emotional reactions to this historic moment highlights the pivotal role television now plays in shaping not only the culture's use of the hero but also in the broader influence in the very fabric of cultural memory.

I identify the bombing of Afghanistan as pivotal in the transformation of the cultural climate from that of traumatized grief with its feelings of victimization and powerlessness into a renewed sense of empowerment and a socially shared resistance to the mourning process. This moment was crucial in solidifying a cultural psychological barrier from those still in trauma and grief. That moment also presaged what would come to pass a year and half later with the American attack on Iraq, the re-shaping of the collective memory from one marked by grief and helplessness into one of social injustice and retribution, a conversion of sorrow, helplessness and vulnerability into anger and revenge, a disruption of the inward nature of the mourning process. This looking outward, beyond our inner and outer boundaries, signaled the downfall of the firefighter as a hero.

With so little actual body recovery, with the failure to bomb Bin Laden out of hiding, the collective could no longer bear feelings of defeat and helplessness. This contrasted sharply with those who were actively engaged in the recovery effort, who, because they were 'doing something,' felt less helpless. Transforming the pain and helplessness of grief and trauma into 
aggression and war was our collective solution to what had happened. As Elias Canetti (1962) put it,

It is the first death which infects everyone with the feeling of being threatened...in kindling of wars. (p. 138)

Our heroes, the firemen, in their tireless but doomed recovery search, then symbolized those aspects of the collective experience that the society was disavowing: defeat, helplessness, and unrelenting pain and sorrow. In continuing to carry the mask of grief, the faces of the firemen negated the face of power and surface aliveness that bellicosity affords.

With American military presence fully installed in Afghanistan, Americans could disconnect from the intolerable and ego dystonic emotions of vulnerability and helplessness. They could turn on their televisions and see the faces of victorious soldier heroes in battle rather than those of our tragic firemen heroes unable to recover more of our lost persons. With the failure to capture Bin Laden and with society's need to dissociate from reminders of trauma and catastrophic grief that were so indelibly installed onto the firemen of New York City, and in our craving for a restored sense of strength, invincibility, and aliveness, society began to become disillusioned with our 9/11 heroes.

Over the next year or two, the firefighters continued to reflect the damage that had been inflicted on us as a nation. Their inability to psychologically recover at a pace in keeping with societal demands was evidenced in their ongoing emotional and physical traumatization. Thus, they were no longer tenable as heroes, able to symbolize what we needed them to reflect of our national condition. With a full-scale war in Iraq, we had created a new hero, the American soldier. By the time of this writing, in 2005, the glimmers of disillusionment with our new heroes had already begun to surface, with society having to confront the faltering image of the American military, such as in Abu Graib and Guantanamo.

The concept of aborted mourning through retribution and vengeance is not a new idea but it has long evaded solution, at the intrapsychic, interpersonal, or larger social level. I have no significant new suggestions to offer to the challenge of collective's mourning process, societal need to both remember and forget, or to the collective impulse to revert to aggression and vengeance, and to abort mourning, through seeking redress and justice for social trauma. However, it seems to me that the building and perpetuating of physical and psychological barriers impedes embodied experience and full comprehension of the reality of mass murder and socially inflicted trauma, and violence in general, at either the individual or broader social level. This includes the social creation and manipulation of heroes and enemies as a social tool. As natural as it may be as a social 
phenomenon, driven by splitting and dissociation, these patterns inhibit aliveness and intra-psychic integration, interpersonal growth, and most importantly, it puts the society at risk of repeating the very violence it has been subjected to.

\section{CONCLUSION}

The culture's transformation of itself and its heroes after September 11th was a process that began very early in the post $9 / 11$ period. How a society relates to pain, how it overcomes trauma and tragedy, how it mourns, informs its doing and undoing of the heroes it creates. To the extent America as a society cannot fully mourn and confront our own feelings of helplessness and vulnerability, we are susceptible to counter phobic denial, disavowal, and dissociation, which expresses itself in interpersonal distancing from those who symbolize these unacceptable aspects of self. The New York City firefighter as the hero of 9/11 was a condensation of contrary attributes, simultaneously symbolizing life and death, victimization and survival, and the poignancy of courage in defeat. America's self-image, however, as a nation is incompatible with either defeat or victimization. In our commitment to a sense of invulnerability and invincibility, we could not sustain our connection to those heroes who continued to embody and bear the aftereffects of trauma and tragedy. Without a cultural precedent for coping with such a massive loss of life as the country sustained on September 11th, and without strong cultural traditions for longer term mourning, as a collective we had to separate from the vanquished hero firefighter of the FDNY. We had to regroup, and in our need to dissociate from pain and grief, we turned to the kind of common man hero with whom we much prefer to identify: the conquering soldier.

In the immediacy of crisis, the hero serves a healing function, as a kind of transitional object, a comforting presence in the face of loss. But when the hero cannot transit into the emotional state which reflects that of the society which has created him, the hero will no longer serve the culture. While in the first days and weeks following $9 / 11$, the image of the firefighters was one which comforted and re-vitalized a shocked and grief-stricken nation, when they continued to be in the grip of death immersion, catastrophic grief, and trauma's psychological impact, they came to be perceived by society as contaminated carriers of a historical truth the collective felt compelled to disavow. Namely that of America and Americans as vulnerable.

The real men behind the heroic face of the Fire Department of New York could no longer symbolize society's search for redemption. As history has repeatedly shown, societies go to war to redress and redeem injury and 
trauma and as a culturally sanctioned means of mourning, especially when in a state of continuing fear. But with recent events at Abu Graib and Guantanamo, with the faltering of our latest heroes, the American soldiers, and disillusionment setting in over the war in Iraq, all the while the threat of terrorism remains unmitigated, how can we as a society deal with our feelings without disconnecting from those people, victims and heroes alike, who are living symbols of that which we find difficult in ourselves? How do we develop more effective ways to mourn and to live with ongoing fear? Can we as a society not only survive but also really overcome the historical trauma that was September 11th?

\section{REFERENCES}

Becker, E. (1973). The denial of death. New York: Free Press.

Bennett, S. (2004). Psychoanalytic reflections on heroism in a time of fallen heroes. Journal of Nervous and Mental Disease, 192(3), 171-177.

Campbell, J. (1976) In J. McGinniss (Ed.), Heroes (p. 27). New York: Viking Press.

Canetti, E. (1962). Crowds and power. New York: Viking, (p. 138).

Cowen, T. (2000). The new heroes and role models. Reason, 30(1), 30.

Elsaesser, T. (2002). One train may be hiding another: History, memory, identity and the visual image. In L. Belau \& P. Ramadanovic (Eds.), Topologies of trauma: Essays in the limits of knowledge and memory. New York: Other Press.

Erikson, K. (1995). Notes on trauma and community. In C. Caruth (Ed.) Trauma: Explorations in memory. Baltimore \& London: The Johns Hopkins University Press.

Goren, E. (2002). A call to bear witness. The Psychoanalyst Activist, 6, 1-8.

Goren, E. (2004). From heroes to zeroes: Psychoanalysis and firemen post 9/11. Paper presented to Division 39, American Psychological Association, March 2004.

Goren, E.R. (2003). America's love affair with technology: The transformation of sexuality and the self over the twentieth century. Psychoanalytic Psychology, 20, 487-508.

Hein, D. (1993). The death of heroes, the recovery of the heroic. Christian Century, December 22, 1993.

Laub, D. \& Auerhahn, N.C. (1993). Knowing and not-knowing massive psychic trauma: Forms of traumatic memory. International Journal of Psychoanalysis, 74, 287-302.

McGinniss, J. (1976). Heroes. New York: Viking Press.

Sontag, S. (2003). Regarding the pain of others. New York: Farrar, Straus and Giroux.

Thomas, N.K. (2005). The use of the hero. In Y. Danieli \& R. L. Dingman (Eds.) On the ground after September 11: Mental health responses and practical knowledge gained. Binghamton, NY: Haworth Press.

Wilson, M. \& Mclntire, M. (2004). Firefighters lash out at commissioners, angering Bloomberg. New York Times. December 8. 